\title{
A Total Synthesis of Salinosporamide A
}

\author{
Léo B. Marx, ${ }^{[a]}$ and Jonathan W. Burton ${ }^{*[a]}$
}

\begin{abstract}
Salinosporamide $A$ is a $\beta$-lactone proteasome inhibitor currently in clinical trials for the treatment of multiple-myeloma. Herein we report a short synthesis of this small, highly functionalized, biologically important natural product that uses an oxidative radical cyclization as a key step and allows the preparation of gram quantities of advanced synthetic intermediates.
\end{abstract}

\section{Introduction}

In 2003, Fenical and co-workers reported the isolation, structure determination and cancer cell cytotoxicity of the marine-derived

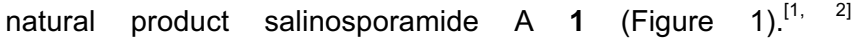
Salinosporamide A, is structurally closely related to omuralide $\mathbf{2}$, the ring-closed form of lactacystin $\mathbf{3}$, in that they both contain a pyrrolidinone fused to a $\beta$-lactone which is key to their biological activity. Both $\mathbf{1}$ and $\mathbf{2}$ are small molecule proteasome inhibitors whose mechanism of action involves esterification of an $\mathrm{N}$ terminal threonine residue of the $20 \mathrm{~S}$ proteasome by the electrophilic $\beta$-lactone. ${ }^{[3]}$ Given the higher proteasome activity exhibited by cancer cells, proteasome inhibition is an active area of research for cancer chemotherapy. Indeed, salinosporamide A has entered clinical trials for the treatment of multiple-myeloma, solid tumors or lymphoma. ${ }^{[4,5]}$
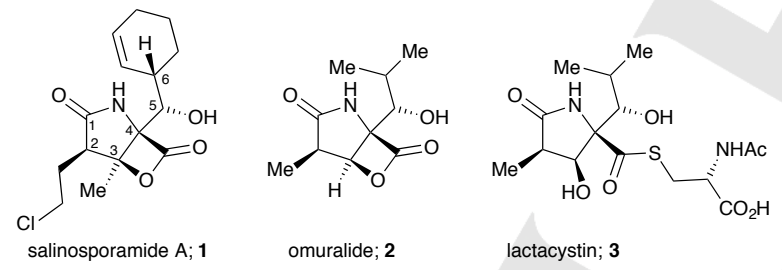

Figure 1. Salinosporamide A, omuralide and lactacystin.

This biologically important natural product presents a significant challenge to synthetic chemists as it contains a high concentration of both electrophilic and nucleophilic functional groups within a small [3.2.0]-bicyclic core containing five contiguous stereocenters including adjacent quaternary centers. The biological activity exhibited by 1 coupled with its interesting structure has resulted in nine total syntheses of the natural

[a] Dr L. B. Marx, Dr J. W. Burton

Department of Chemistry, University of Oxford, Chemistry Research Laboratory, Mansfield Road, Oxford OX1 3TA UK

E-mail: jonathan.burton@chem.ox.ac.uk

Supporting information for this article is given via a link at the end of the document. product in enantiopure form. ${ }^{[6-9]}$ It is surprising, given all of the advances in synthetic methodology over the previous decades, that only three of the reported total syntheses of salinosporamide A (1) have fewer than 20 steps and a number have greater than 30 steps. These step counts, subjective as they may be, demonstrate the synthetic challenge that such a densely functionalized, stereochemically rich molecule presents. Herein we report a novel 16 step (9 chromatographed intermediates) stereocontrolled synthesis of salinosporamide A (1) that features an oxidative radical cyclization and a selenolactonization as key steps and provides gram quantities of key synthetic intermediates.

\section{Results and Discussion}

\section{Retrosynthetic Analysis}

Our retrosynthetic analysis of salinosporamide A (1) is delineated in Scheme 1. In the first synthesis of salinosporamide $A,{ }^{6 a}$ Corey reported an elegant method to install the C-5 and C- 6 stereocenters of 1 that involved addition of a cyclohexenylzinc reagent to a [4.3.0]-bicyclic aldehyde. Variations of this method have been used by the majority of researchers to set the $\mathrm{C}-5$ and C- 6 stereocenters of 1 and we elected to investigate this method for our synthesis. We therefore decided to synthesize salinosporamide A (1) from the lactone-lactam 4 which would, in turn, be made from the fused bicyclic aldehyde $\mathbf{5}$ on addition of the appropriate cyclohexenyl organometallic. Taking our cue from Danishefsky's synthesis of salinosporamide $A^{6 c}$ (the second synthesis of the natural product), we reasoned that the $C$ - 3 tertiary alkoxy-bearing stereocenter could be installed by selenolactonization onto the 1,1-disubsituted alkene contained within $\mathbf{6}$. The alkene $\mathbf{6}$ would itself be prepared from the selenide 7 with the selenide being formed by nucleophilic opening of the [3.3.0]-bicyclic $y$-lactone 8. A key step in our synthesis of salinosporamide $A$ was to be the oxidative radical cyclization of the amidomalonate 9 to give 8 . We have recently shown that $\mathrm{N}$ PMB-protected amidomalonates bearing pendent alkenes form [3.3.0]-bicyclic $y$-lactones under oxidative radical conditions and used this methodology in our formal synthesis of $1 .^{89}$ All of the previous syntheses of salinosporamide $A(1)$ have, at some point involved, protection of the lactam $\mathrm{NH}$ (frequently as an $\mathrm{N}$-PMB group $)^{[6-9]}$ and it appeared that such lactam protection was crucial to the successful synthesis of salinosporamide A (1); our first target was therefore the tertiary amide $9 a$ (with the choice of ester to be determined by experiment). In the event, we found that the secondary amide $9 b\left(R=M e\right.$ or $\left.t B u, R^{\prime}=H\right)$ was a competent substrate for oxidative radical cyclization to form the [3.3.0]bicyclic $\mathrm{Y}$-lactone $\mathbf{8 b}\left(\mathrm{R}=\mathrm{Me}\right.$ or $\left.t \mathrm{Bu}, \mathrm{R}^{\prime}=\mathrm{H}\right)$ and we carried the unprotected amide/lactam through the complete synthetic sequence to the natural product itself (vide infra). 


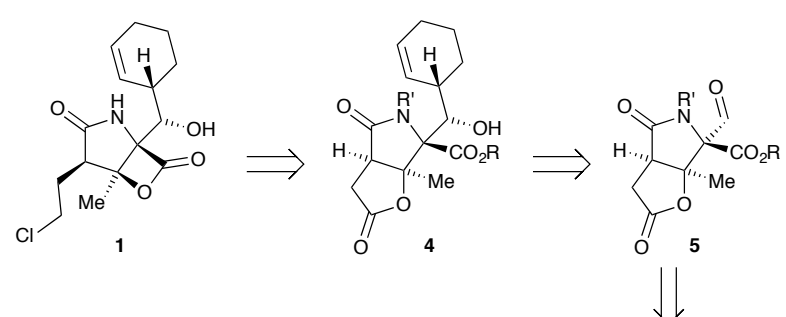

tBuO$C^{\mathrm{C}}$

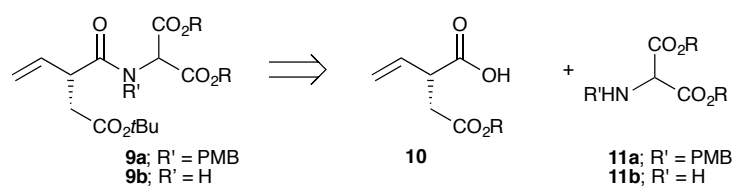

Scheme 1. Retrosynthetic analysis of salinosporamide A (1).

\section{Synthesis}

We initially prepared the carboxylic acid 14 in $73 \%$ yield by alkylation of the known oxazolidinone $12^{89}$ using $t$-butyl bromoacetate followed by hydrolysis (Scheme 2). ${ }^{[10]}$ We aimed to convert 14 into the amidomalonate 15 by coupling of the acid chloride derived from 14 with the readily prepared aminomalonate 16 (ESI) under Shotten-Baumann conditions. ${ }^{[6],[11]}$ Thus, exposure of the acid $\mathbf{1 4}$ to oxalyl chloride followed by addition of the amine $16^{8 \mathrm{~g}}$ resulted in quantitative recovery of 16 after workup and formation of the corresponding dicarboxylic acid derived from 14 (mass spectrometry evidence).
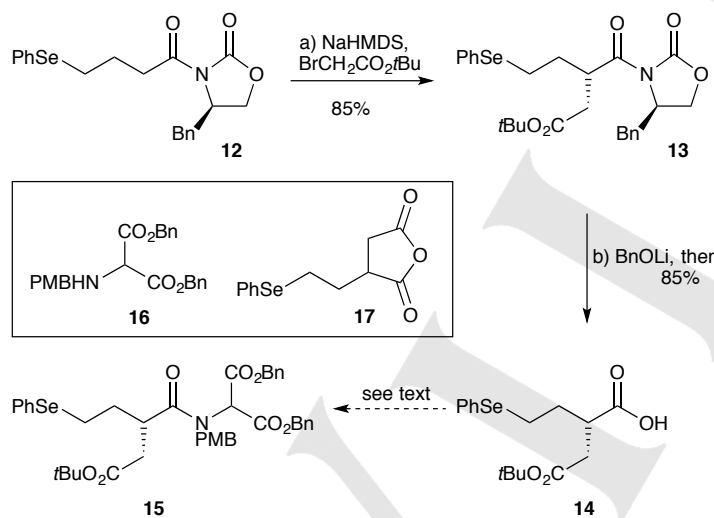

Scheme 2. Synthesis of acid 14. Reagents and conditions: a) NaHMDS, THF, $-78{ }^{\circ} \mathrm{C}, 10 \mathrm{~min}$, then $\mathrm{BrCH}_{2} \mathrm{CO}_{2} \mathrm{tBu},-78^{\circ} \mathrm{C}, 45 \mathrm{~min}, 85 \%$; b) $\mathrm{BnOH}, n \mathrm{BuLi}$, THF, $0{ }^{\circ} \mathrm{C}, 45 \mathrm{~min}$, add $13,-78$ to $0{ }^{\circ} \mathrm{C}$, then $\mathrm{LiOH}, \mathrm{MeOH}$, water, THF, $0{ }^{\circ} \mathrm{C}$ to RT, $16 \mathrm{~h}, 85 \%$.

The failure of this seemingly simple amide bond forming reaction is most likely attributable to the amine 16 being both sterically encumbered, and of reduced nucleophilicity due to the electron withdrawing malonate functionality. Coupling of deactivated amines such as $\mathbf{1 6}$ would require a highly electrophilic activated carboxylic acid component; however, activation of $\beta$-carboxy carboxylic acids (such as 14) can result in the formation of the corresponding anhydrides (e.g. 17). ${ }^{[12,13]}$ Both the formation of 17 coupled with the low nucleophilicity of 16 results in the formation of $\mathbf{1 5}$ being highly challenging. Acid fluorides have been reported to prevent anhydride formation allowing coupling of $\beta$-carboxy carboxylic acids substrates, ${ }^{[13]}$ however, the corresponding acid fluoride derived from $14\left(\mathrm{v}_{\max }=1836 \mathrm{~cm}^{-1}\right)$ failed to undergo amide bond formation with 16 (or derivatives). Indeed, under a wide variety of amide bond forming conditions we failed to form any of the desired product $15 .{ }^{[14]}$ We reasoned that reducing the steric bulk of the amine partner might result in successful amide bond formation. We therefore investigated amide formation between dimethyl aminomalonate 18, with reduced steric hindrance both at nitrogen and at the malonate esters. In the event amide coupling was readily achieved between the acid 14 and dimethyl aminomalonate 18 in the presence of HATU (Scheme 3). Oxidative elimination of the phenylselanyl group from 19 occurred in good yield using a modification of the procedure reported by Kocienski ${ }^{[15]}$ to give cyclization substrate 20. We have previously shown that $N$-PMB protected amidomalonates bearing terminal alkenes readily undergo cyclization to form the corresponding [3.3.0]-bicyclic $y$-lactones and had found that cyclization of simple $\mathrm{N}$-unprotected amidomalonates bearing terminal alkenes was capricious. ${ }^{89}$

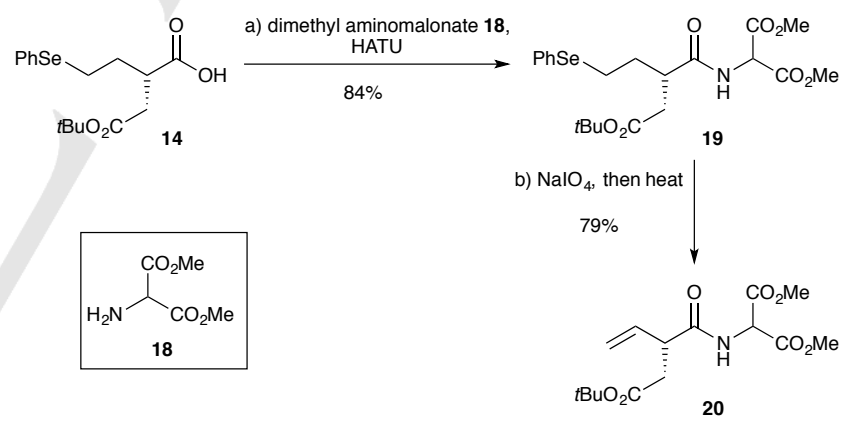

Scheme 3. Synthesis of amide 20. Reagents and conditions: a) dimethyl aminomalonte 18, HATU, $i-\mathrm{Pr}_{2} \mathrm{NEt}$, DMF, $0^{\circ} \mathrm{C}$ to RT, $84 \%$; b) $\mathrm{NalO}_{4}, \mathrm{NaHCO}_{3}$, $\mathrm{MeOH}, \mathrm{THF}$, water, then heat in toluene, $79 \%$.

Given these previous results we were delighted to find that exposure of amidomalonate $\mathbf{2 0}$ to our standard conditions for oxidative radical cyclization ${ }^{[16]}$ resulted in the formation of the desired [3.3.0]-bicyclic $y$-lactone 23a in 48\% yield along with the uncyclized but oxidized products 21 and 22 (Scheme 4). ${ }^{1} \mathrm{H}$ NMR analysis of the crude reaction mixture indicated the [3.3.0]-bicyclic $y$-lactone 23a was formed as an 8:1 mixture along with what was assumed to be diastereomer 23b (based on previous experience). ${ }^{8 g}$ 


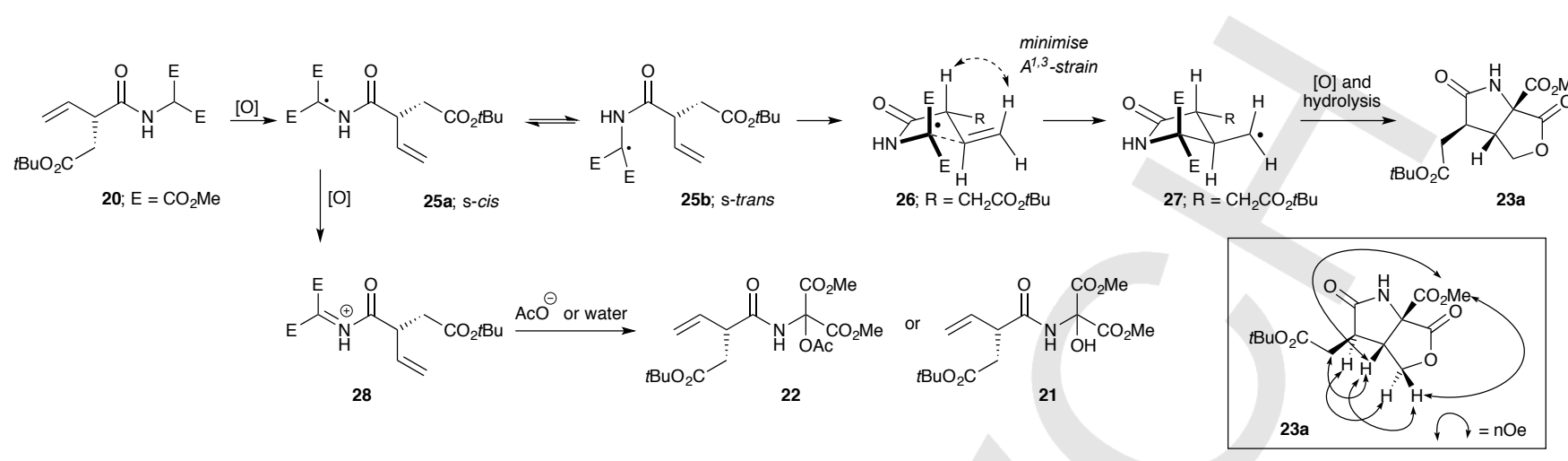

Scheme 5. Plausible mechanism for formation of products $\mathbf{2 1 , 2 2}$ and $\mathbf{2 3 a}$ under oxidative radical conditions and ${ }^{1} \mathrm{H}$ NMR nOes for compound $\mathbf{2 3 a}$

The configuration of the major diastereomer 23a was assigned by ${ }^{1} \mathrm{H}$ NMR nOe experiments (Scheme 5). The formation of the products 21,22 and 23 , most likely arises by oxidation of the substrate 20 with $\mathrm{Mn}^{\mathrm{III}}$ to generate the captodative $C$-centered radical 25 (Scheme 5). ${ }^{[17,18]}$ In order for 5 -exo-trig cyclization to occur from 25 it is necessary for this radical to adopt an s-trans conformation 25b. Secondary amides are well known to adopt an $\mathrm{s}$-cis geometry preferentially and it is likely that the corresponding radical s-cis 25a will also be the lower energy conformation compared with s-trans $\mathbf{2 5 b}$. The s-trans radical $\mathbf{2 5 b}$ can undergo 5-exo-trig cyclization from the pre-transition state assembly $\mathbf{2 6}$ with the carboxymethylene side chain occupying a pseudoequatorial position in the chair-like transition state. ${ }^{[19]}$ The adduct radical $\mathbf{2 7}$ then undergoes oxidation and lactonization to give the product [3.3.0]-bicyclic Y-lactone 23a. Alternatively, competitive oxidation of the captodative radical 25 to the corresponding iminium ion (or imine) $\mathbf{2 8}$ may occur followed by trapping with acetate anion or water giving $\mathbf{2 1}$ and $\mathbf{2 2} .^{[20]}$ The stability of the "tetrahedral intermediates" 21 and 22 is undoubtedly a result of them being the formal addition products to the tricarbonyl compound dimethyl ketomalonate. ${ }^{[21]}$

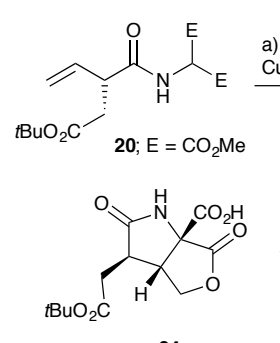

24
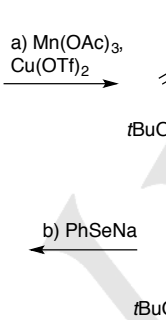

23

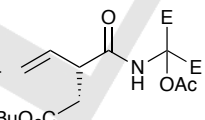

Scheme 4. Initial cyclizations. Reagents and conditions: a) $\mathrm{Mn}(\mathrm{OAc})_{3}, \mathrm{Cu}(\mathrm{OTf})_{2}$, MeCN, reflux; 23a, 48\%; 23b, 5\% (NMR yield); 21, 5-10\% (NMR yield); 22, 5$10 \%$ (NMR yield); b) $(\mathrm{PhSe})_{2}, \mathrm{NaBH}_{4}, \mathrm{DMF}, 100^{\circ} \mathrm{C}$ then add lactone $23 \mathrm{a}, 50{ }^{\circ} \mathrm{C}$, $46 \%$.
The next step in the synthetic pathway required differentiation of the $y$-lactone carbonyl group from the remaining carbonyl groups in 23a. Our synthetic strategy was to open the $y$-lactone with the highly nucleophilic phenylselanyl anion. Unsurprisingly exposure of the [3.3.0]-y-lactone 23a to the anion formed on reduction of diphenyl diselenide with sodium borohydride, ${ }^{[22]}$ resulted in substitution at the methyl ester to give the lactone acid 24 (Scheme 4$) ;{ }^{[23]}$ clearly a more sterically demanding ester group was required.

\section{Synthesis - Second Generation}

The synthesis of the cyclization substrate 20 , and successful cyclization to give the bicyclic $y$-lactones $\mathbf{2 3}$ had demonstrated the feasibility of oxidative radical methodology to form [3.3.0]-bicyclic $\mathrm{Y}$-lactones from terminal alkene-containing secondary amidomalonates. However, it was clear that a change of malonate ester was required and we elected to use a di-tert-butyl malonate as Danishefsky had demonstrated that tert-butyl esters were compatible with lactone opening by the phenylselanyl anion. ${ }^{[6],[23]}$ Additionally, we sought a shorter synthesis of the acid coupling partner 10. As shown in the retrosynthetic analysis (Scheme 1) we intended to synthesize the cyclization substrates by direct amide bond formation between the enantiopure $\beta, \gamma-$ unsaturated acid 10 and aminomalonates represented by $\mathbf{1 1 b}$. We were fully aware that this might be a challenging amide bond formation due to the reduced nucleophilicity of the amine $11 \mathrm{~b}$ and the distinct possibility of epimerization of the stereocenter in $\mathbf{1 0}$ during amide bond formation. Our first task was to synthesize the acid, represented by $\mathbf{1 0}$, in enantiopure form.

Oppolzer has reported that treatment of the enolate derived from the $\beta, \gamma$-unsaturated sultam 29 (Scheme 6 ) with benzyl bromide gave the corresponding a-benzylated product in good yield $(80 \%)^{[24]}$ and excellent diastereoselectivity. Additionally, the deconjugative methylation of the enolate derived from the sultam 31 has been reported by Golec. ${ }^{[25]}$ Following these precedents, treatment of the crotonyl substituted sultam 31 with LiHMDS followed by the addition of tert-butyl bromoacetate gave the sultam 32 in $88 \%$ yield and $>20: 1$ diastereomeric ratio as a white crystalline solid. Hydrolysis using hydroperoxide anion ${ }^{[26]}$ gave the desired carboxylic acid $\mathbf{3 3}$. The auxiliary $\mathbf{3 0}$ was separated 
from 33 by trituration with hexane giving the acid in $91 \%$ yield (90\% purity, $98.8 \%$ ee). The next challenge was to develop a racemization free amide bond forming reaction between the chiral non-racemic acid $\mathbf{3 3}$ and the amine 34 . Initial trials using HATU with either DIPEA or $\mathrm{N}$-methylmorpholine as added base resulted in the product 35 being isolated in $70-75 \%$ ee. Ringling recently advocated the use of T3P (propylphosphonic anhydride) as a mild reagent for racemization free amide bond formation. ${ }^{[27]}$ Following Ringling's procedure, with a reaction temperature of $0{ }^{\circ} \mathrm{C}$, gave the amide 35 with $96 \%$ ee, while lowering the temperature to $-40{ }^{\circ} \mathrm{C}$ gave the desired product 35 in $65 \%$ yield $(98.4 \%$ ee) from the sultam 32. This short synthetic sequence allowed for the preparation of multigram quantities of the cyclization substrate 35 with high yield and enantiomeric purity.

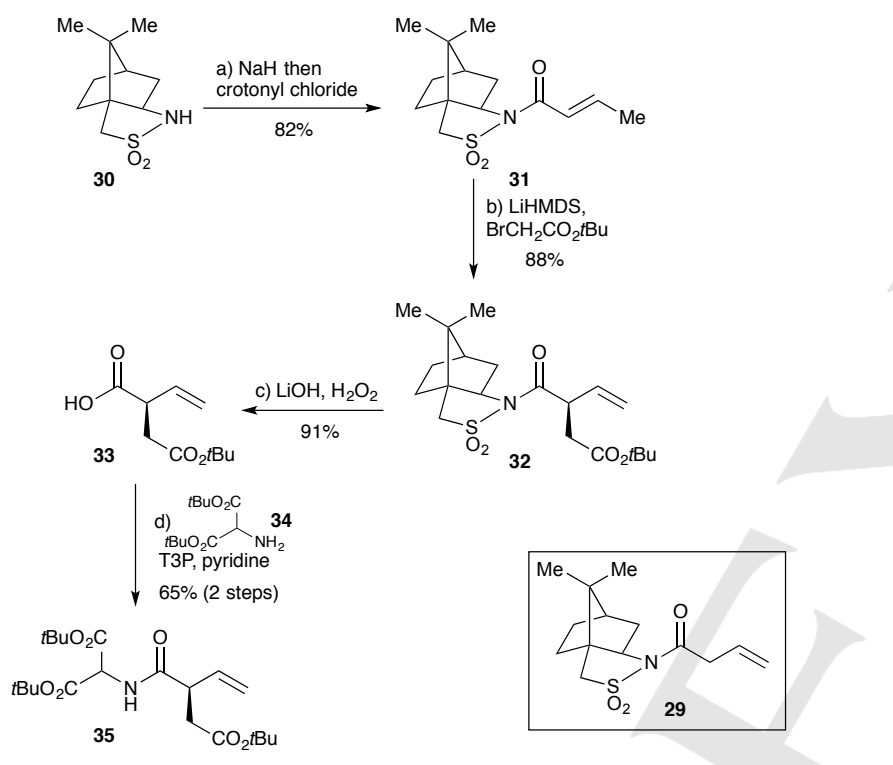

Scheme 6. Synthesis of amine 35. Reagents and conditions: a) $\mathrm{NaH}$, toluene, $0{ }^{\circ} \mathrm{C}$ to RT then add crotonyl chloride, $0{ }^{\circ} \mathrm{C}$ to RT, $2 \mathrm{~h}, 82 \%$; b) LiHMDS, THF, HMPA, $-78{ }^{\circ} \mathrm{C}$, 30 min then $\mathrm{BrCH}_{2} \mathrm{CO}_{2} \mathrm{tBu}$, THF $-78{ }^{\circ} \mathrm{C}, 7 \mathrm{~h}, 88 \%$; c) $30 \% \mathrm{H}_{2} \mathrm{O}_{2}$, $\mathrm{LiOH}$, THF, water, $5 \mathrm{~min}, 91 \%$; d) 34, T3P $\left\{\left[\mathrm{CH}_{3} \mathrm{CH}_{2} \mathrm{CH}_{2} \mathrm{OP}(\mathrm{O})\right]_{3}\right\}$, pyridine, EtOAc, -40 to $-10^{\circ} \mathrm{C}, 6 \mathrm{~h}, 65 \%$ from 32 .

\section{Cyclization Optimization}

Having developed an efficient synthesis of the cyclization substrate optimization of the oxidative radical cyclization was required. Initial studies using racemic substrate $( \pm)-35$ with 2 equivalents of $\mathrm{Mn}(\mathrm{OAc})_{3}$ and 1 equivalent of $\mathrm{Cu}(\mathrm{OTf})_{2}$ in acetonitrile at $80{ }^{\circ} \mathrm{C}$ gave the desired [3.3.0]-bicyclic $\mathrm{Y}$-lactones $( \pm)-36$ in $50-60 \%$ yield as a $>8: 1$ mixture of $\mathrm{C}-2$ diastereomers along with the oxidized and uncyclized material $( \pm)-38$. Changing the amount of $\mathrm{Cu}^{\text {Il }}$ salt had little influence on the outcome of the reaction. We moved to using cheaper $\mathrm{Cu}\left(\mathrm{BF}_{4}\right)_{2}$ and found that the amount of water in the reaction mixture had an influence on the product distribution of the reaction (Table 1). With no added water in the reaction the desired lactones $( \pm)$-36 were formed as a 9:1 mixture along with the methylene pyrrolidinone $( \pm$ )-37 (Table 1 , entry 1). Addition of water lead to increasing quantities of the oxidized, but uncyclized malonate $( \pm$ )-38 being formed (entries 2 -
5). Although the influence of water was not profound, the best yield of bicyclic lactone ( \pm )-36 was found using a $50: 3$ ratio of acetonitrile to water (entry 4 ). Pleasingly, these conditions were transferable to gram scale with ready separation of the C-2 lactone diastereomers of $\mathbf{3 6}$ being achieved (entry 6). During optimization of the cyclization the reaction was also conducted on $5 \mathrm{~g}$ of enantiopure material using a 9:1 ratio of acetonitrile:water which gave the bicyclic lactone in $67 \%$ isolated yield (entry 7 ). Although it is not immediately clear as to the reason for water influencing the product distribution in the reaction of 35 , we postulate that the amount of water affects the oxidation potential of the copper(II) salt which in turn could influence the product distribution.

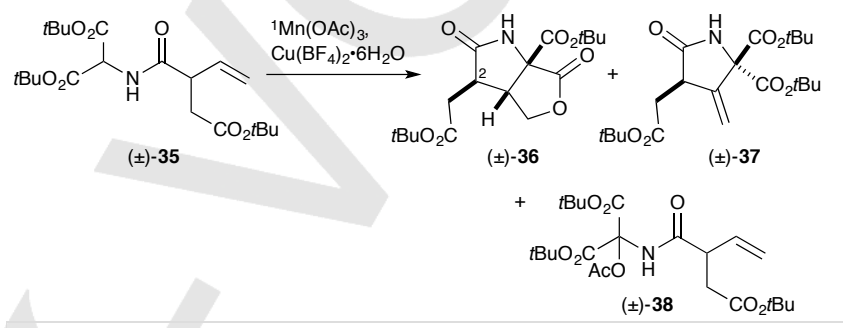

Table 1. Optimization of the cyclization of substrate $( \pm)-35$ with respect to water content.

\begin{tabular}{|c|c|c|c|c|c|}
\hline Entry $^{[a]}$ & $\begin{array}{l}\text { MeCN/ } \\
\text { water }\end{array}$ & $\begin{array}{l}( \pm)-36 \\
\text { crude } \%{ }^{[b]}\end{array}$ & $\begin{array}{c}( \pm)-36 \\
\text { isolated \% }{ }^{[c]}\end{array}$ & $\begin{array}{c}\quad( \pm)-37 \\
\text { crude } \%{ }^{[b]}\end{array}$ & $\begin{array}{c}( \pm)-\mathbf{3 8} \\
\text { crude } \%{ }^{[b]}\end{array}$ \\
\hline 1 & $50: 0$ & 89.5 & 65 & 10.5 & 0 \\
\hline 2 & $50: 1$ & 93.2 & 76 & 4.7 & 2.1 \\
\hline 3 & $50: 2$ & 95.2 & 74 & 1.8 & 3.0 \\
\hline 4 & $50: 3$ & 94.8 & 78 & 1.5 & 4.7 \\
\hline 5 & $50: 5$ & 93.1 & 74 & 0.4 & 6.5 \\
\hline $6^{[d]}$ & $50: 3$ & n.d. ${ }^{[f]}$ & $80(71)^{[\mathrm{g}]}$ & n.d. & n.d. \\
\hline $7^{[\mathrm{e}]}$ & $50: 5.5$ & n.d. ${ }^{[f]}$ & $67^{[\mathrm{g}]}$ & n.d. & n.d. \\
\hline
\end{tabular}

[a] $\mathrm{Mn}(\mathrm{OAc})_{3} \cdot 2 \mathrm{H}_{2} \mathrm{O}$ (3.0 equiv.), $\mathrm{Cu}\left(\mathrm{BF}_{4}\right)_{2} \cdot 6 \mathrm{H}_{2} \mathrm{O}$ (0.3 equiv.), $\mathrm{MeCN} / \mathrm{H}_{2} \mathrm{O}$ (see column 2 for proportions), $105{ }^{\circ} \mathrm{C}$ (oil bath temperature), $30 \mathrm{~min}, 500 \mathrm{mg}$ and $0.25 \mathrm{M}$ in substrate. [b] mol\% from crude ${ }^{1} \mathrm{H}$ NMR spectrum. [c] Total isolated yield of an 8.5-9.5:1 mixture of $\mathrm{C}-2$ diastereomers (natural product numbering, major diastereomer shown). [d] Reaction conducted on $4.06 \mathrm{~g}, 9.82 \mathrm{mmol}$ of material of $82 \%$ ee. [e] Reaction conducted on $5.93 \mathrm{~g}, 14.4 \mathrm{mmol}$ of material of $>98 \%$ ee. [f] n.d. = not determined. [g] Yield of isolated pure single (2R)diastereomer $(+)-36$.

Optimization of the cyclization had given us access to gram quantities of the enantiopure [3.3.0]-bicyclic $y$-lactone (+)-36. The next step in the synthesis involved opening of the $\gamma$-lactone by phenylselanyl anion. Attempted opening of the $y$-lactone in $(+)-$ 36 by exposure to phenylselanyl anion, formed by the reduction of diphenyldiselenide with sodium borohydride, in DMF at $100^{\circ} \mathrm{C}$ led to decomposition whereas no reaction was observed at $50^{\circ} \mathrm{C}$. Liotta showed that a non-complexed, and hence more nucleophilic anion is formed by reduction of diphenyl diselenide by sodium metal, or deprotonation of benzeneselenol with sodium 
hydride.$^{[28]}$ Pleasingly exposure of the enantioenriched $y$-lactone $(+)-36$ to phenylselanyl anion prepared by reduction of diphenyl diselenide with sodium hydride ${ }^{[29]}$ allowed reaction at room temperature to give the fully substituted pyrrolidinone $\mathbf{3 9}$ after acid base extraction (Scheme 7). Reduction of the carboxylic acid in 39 to the corresponding primary alcohol $\mathbf{4 0}$ proved problematic with direct reduction using borane resulting in substrate decomposition and attempted reduction of the corresponding mixed anhydride with sodium borohydride resulting in numerous uncharacterized products being formed.
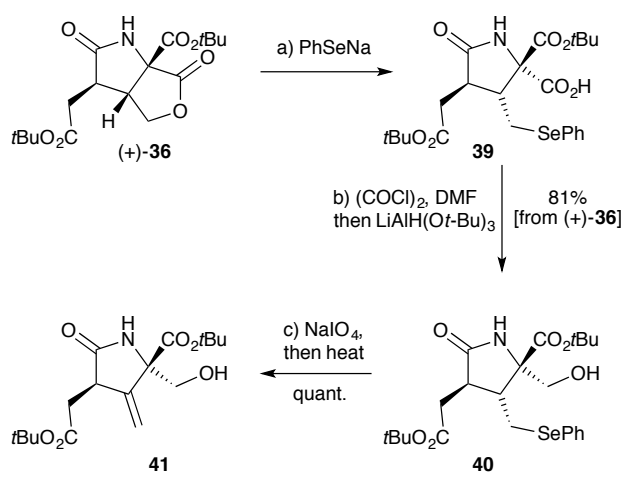

Scheme 7. Synthesis of pyrrolidinone 41. Reagents and conditions: a) (PhSe $)_{2}$, $\mathrm{NaH}, \mathrm{THF}, 65^{\circ} \mathrm{C}, 90 \mathrm{~min}$, then (+)-36, 18 -crown-6, $0{ }^{\circ} \mathrm{C}$ then RT, $3 \mathrm{~h}$; b) $(\mathrm{COCl})_{2}$, DMF, then $\mathrm{LiAlH}(\mathrm{OtBu})_{3}$, THF, MeCN, $-78{ }^{\circ} \mathrm{C}$ to RT, 81\% from (+)-36; c) $\mathrm{NaIO}_{4}$, $\mathrm{NaHCO}_{3}, \mathrm{THF}, \mathrm{MeOH}$, water, RT, then $\mathrm{CHCl}_{3}$, reflux, quant.

Ultimately, we found that conversion of the acid 39 into the corresponding acid chloride followed by reduction with lithium tritert-butoxy aluminum hydride ${ }^{[30]}$ gave the primary alcohol $\mathbf{4 0}$ in $81 \%$ yield from the bicyclic lactone (+)-36. Elimination of the phenylselanyl group from $\mathbf{4 0}$ was achieved by oxidation and thermal treatment to give the alkene $\mathbf{4 1}$ in quantitative yield. All that remained for the synthesis of the fully functionalized pyrrolidinone core of salinosporamide A 1 was installation of the C-3 tertiary hydroxyl/alkoxy group.

The lactonization of the ester alkene $\mathbf{4 1}$ (for example to give $\mathbf{4 2}$ Scheme 8) was crucial to our synthetic strategy. After extensive experimentation, we found that lactonization could be achieved using the phenylselanyl cation as reported by Danishefsky for a closely related selenocyclo-acetalization. ${ }^{6 c}$ Thus, exposure of the alkene $\mathbf{4 1}$ to phenylselanyl bromide and silver $(\mathrm{I})$ tetrafluoroborate led to lactonization with concomitant loss of the tert-butyl ester to give the $\mathrm{y}$-lactone $42\left(\mathrm{v}_{\max } 1780 \mathrm{~cm}^{-1}\right)$ in $90 \%$ yield (Scheme 8); the free carboxylic acid was readily converted into the corresponding PMB ester $\mathbf{4 3}$ and the phenylselanyl group was reduced under radical conditions to give 44. Stereoselective introduction of the cyclohexenyl side-chain, conversion of the $\gamma^{-}$ lactone into the $\mathrm{C}-2$ chloroethyl group and $\beta$-lactone formation were now required to complete the synthesis of salinosporamide $A(1)$.
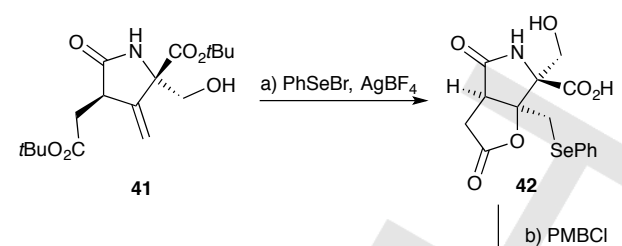

b) $\mathrm{PMBCl}$
$84 \%$ from 41
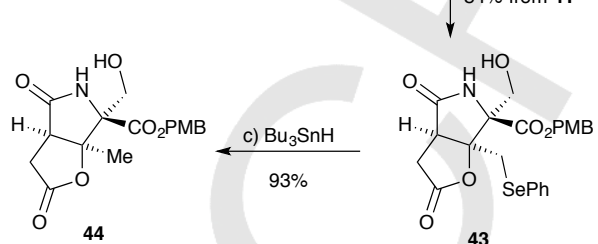

Scheme 8. Synthesis of bicyclic lactone 44. Reagents and conditions: a) $\mathrm{PhSeBr}, \mathrm{AgBF}_{4}, \mathrm{CH}_{2} \mathrm{Cl}_{2}, \mathrm{CH}_{3} \mathrm{CN}, \mathrm{RT}$; b) $4-\mathrm{CH}_{3} \mathrm{O}\left(\mathrm{C}_{6} \mathrm{H}_{4}\right) \mathrm{CH}_{2} \mathrm{Cl}, \mathrm{K}_{2} \mathrm{CO}_{3}, \mathrm{DMF}$, $40{ }^{\circ} \mathrm{C}, 84 \%$ from 41 ; c) $\mathrm{Bu}_{3} \mathrm{SnH}$, AIBN, toluene, $105^{\circ} \mathrm{C}, 93 \%$.

As part of optimizing the synthetic route we had prepared the tertbutyl ester ( \pm )-45 (inset Scheme 9) in racemic form and we used this material to investigate the oxidation and cyclohexenylation reaction following the excellent precedent from Corey. ${ }^{6 a, b}$ We initially investigated the formation of the aldehyde derived from oxidation of $( \pm)-\mathbf{4 5}$. Using standard reagents such as the DessMartin periodinane, pyridinium chlorochromate, or DMSO with pyridine•sulfur trioxide, followed by the usual aqueous workup, either led to no reaction (PCC) or to decomposition. This was surprising given that in a number of previous syntheses of salinosporamide $A(1)$, oxidation of related primary alcohols to the corresponding aldehydes had been readily achieved using DMP; however, in all of these cases, the pyrrolidinone nitrogen atom was protected with either a benzyl-type protecting group or a carbamate protecting group. Interestingly we found that ${ }^{1} \mathrm{H}$ NMR analysis of the oxidation of ( \pm )-45 by DMP in $d_{2}$-dichloromethane showed clean conversion to the corresponding aldehyde (not shown) in under one hour. Addition of water to the reaction mixture followed by ${ }^{1} \mathrm{H}$ NMR analysis showed clear decomposition of the aldehyde, as did direct elution of the reaction mixture through silica or basic alumina. In a similar manner, ${ }^{1} \mathrm{H}$ NMR analysis of the DMP oxidation of alcohol 44 , in both $d_{2-}$ dichloromethane and $d_{8}$-THF demonstrated clean conversion to the corresponding aldehyde (not shown). We therefore developed a one-pot oxidation, alkylation procedure. Treatment of the alcohol 44 with 2 equivalents of DMP in THF at ambient temperature followed by cooling of the reaction mixture to $-78^{\circ} \mathrm{C}$ and addition of 10 equivalents of cyclohexenylzinc bromide $46^{7 c}$ gave the desired product $\mathbf{4 7}$ as a single diastereomer in $56 \%$ yield from the alcohol 44 (Scheme 9 ). This reaction was conducted with $>900 \mathrm{mg}$ of alcohol 44 giving $>600 \mathrm{mg}$ of the cyclohexenylsubstituted product $\mathbf{4 7}$. Reduction of the $\mathrm{y}$-lactone in $\mathbf{4 7}$ to the corresponding diol $\mathbf{4 8}$ in the presence of the lactam and PMBester was the next challenge. Lam $^{8 b}$ had shown that reduction of the $\mathrm{y}$-lactone in the N-PMB protected, methyl ester analogue of 47 , occurred in $60 \%$ yield on treatment with two equivalents of 


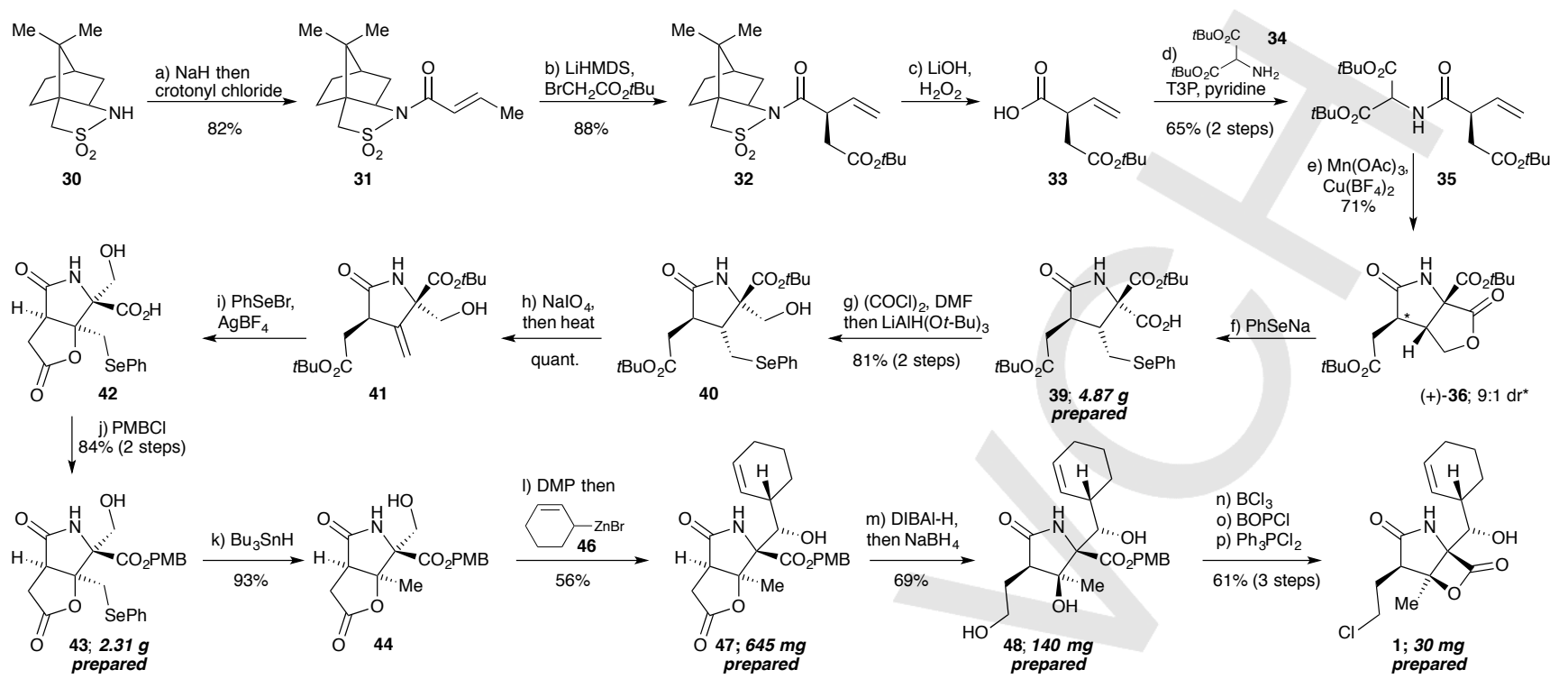

Scheme 10. Total synthesis of salinosporamide A 1. Reagents and conditions: a) NaH, toluene, RT then add crotonyl chloride, $0{ }^{\circ} \mathrm{C}$ to RT, $2 \mathrm{~h}, 82 \%$; b) LiHMDS, THF, HMPA, $-78{ }^{\circ} \mathrm{C}, 30$ min then $\mathrm{BrCH}_{2} \mathrm{CO}_{2} t \mathrm{Bu}$, THF $-78{ }^{\circ} \mathrm{C}, 7 \mathrm{~h}, 88 \%$; c) $30 \% \mathrm{H}_{2} \mathrm{O}_{2}, \mathrm{LiOH}$, THF, water, 10 min, $91 \%$; d) $34, \mathrm{~T} 3 \mathrm{P}\left\{\left[\mathrm{CH}_{3} \mathrm{CH} \mathrm{CH}_{2} \mathrm{P}(\mathrm{O}) \mathrm{O}\right]_{3}\right\}$, pyridine, EtOAc, -40 to $-10{ }^{\circ} \mathrm{C}, 6 \mathrm{~h}, 65 \%$ from $\left.32 ; \mathrm{e}\right) \mathrm{Mn}(\mathrm{OAc})_{3} \cdot 2 \mathrm{H}_{2} \mathrm{O}$ (3.0 equiv.), $\mathrm{Cu}\left(\mathrm{BF}_{4}\right)_{2} \cdot 6 \mathrm{H}_{2} \mathrm{O}\left(0.3\right.$ equiv.), MeCN, water, $71 \%$ (desired diastereomer); f) $(\mathrm{PhSe})_{2}, \mathrm{NaH}$, $\mathrm{THF}, 65^{\circ} \mathrm{C}, 90 \mathrm{~min}$, then (+)-36, 18-crown-6, $0{ }^{\circ} \mathrm{C}$ then RT $\left.3 \mathrm{~h} ; \mathrm{g}\right)(\mathrm{COCl})_{2}$, DMF, then $\mathrm{LiAlH}(\mathrm{OtBu})_{3}, \mathrm{THF}, \mathrm{MeCN},-78^{\circ} \mathrm{C}$ to RT, $81 \%$ from $(+)-36$; $\left.\mathrm{h}\right) \mathrm{NalO}{ }_{4}, \mathrm{NaHCO}{ }_{3}$, THF, $\mathrm{MeOH}$, water, RT, then $\mathrm{CHCl}_{3}$, reflux, quant; i) $\mathrm{PhSeBr}, \mathrm{AgBF}_{4}, \mathrm{CH}_{2} \mathrm{Cl}_{2}, \mathrm{CH}_{3} \mathrm{CN}, \mathrm{RT}$; j) $4-\mathrm{CH}_{3} \mathrm{O}\left(\mathrm{C}_{6} \mathrm{H}_{4}\right) \mathrm{CH}_{2} \mathrm{Cl}, \mathrm{K}_{2} \mathrm{CO}_{3}, \mathrm{DMF}^{\circ} 40{ }^{\circ} \mathrm{C}, 84 \%$ from 41 ; $\left.\mathrm{k}\right) \mathrm{Bu} 3 \mathrm{SnH}^{\circ}$ AIBN, toluene, $105{ }^{\circ} \mathrm{C}, 93 \%$. I. Dess-Martin periodinane, THF, RT, then cyclohexenylzinc bromide $46,-78{ }^{\circ} \mathrm{C}, 56 \%$; $\mathrm{m}$ ) DIBAI-H, THF, $-10{ }^{\circ} \mathrm{C}$, then MeOH, then $\mathrm{NaBH}_{4}, \mathrm{MeOH} / \mathrm{THF}, \mathrm{RT}, 69 \%$; n) $\mathrm{BCl}_{3}, \mathrm{CH}_{2} \mathrm{Cl}_{2}, 0{ }^{\circ} \mathrm{C}$. o. bis(2-oxo-3-oxazolidinyl)phosphinic chloride $(\mathrm{BOPCl}), \mathrm{CH}_{2} \mathrm{Cl}_{2}, \mathrm{pyridine}$, then further $\mathrm{BOPCl}, \mathrm{RT}$; p) $\mathrm{Ph}{ }_{3} \mathrm{PCl}$, $\mathrm{CH}_{3} \mathrm{CN}$, pyridine, $\mathrm{RT}, 61 \%$ (3 steps).

sodium borohydride in methanol to give the corresponding triol. Using Lam's procedure on $\mathbf{4 7}$ gave incomplete reduction of the $y$ lactone and a number of other products were formed as evidenced by TLC analysis.

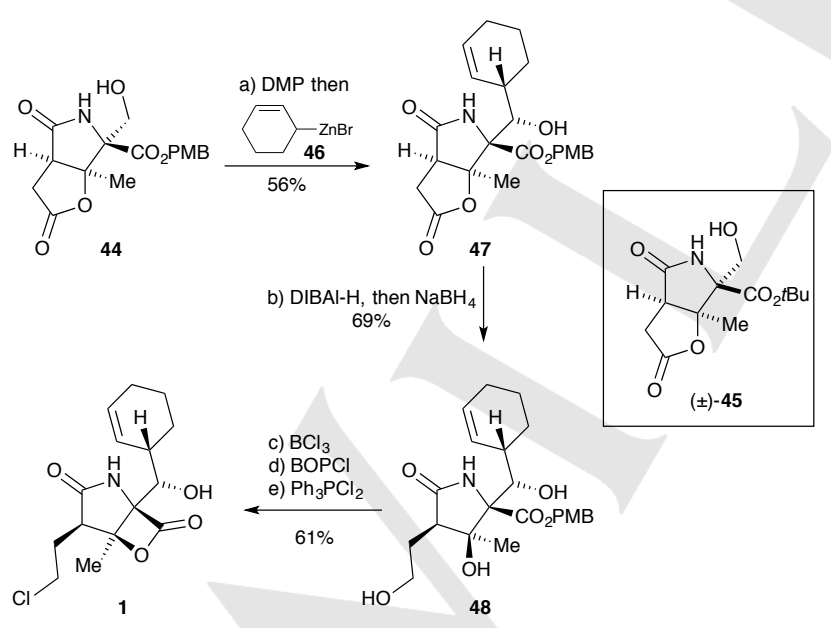

Scheme 9. Completion of the synthesis. Reagents and conditions: a) DessMartin periodinane, THF, RT, then cyclohexenylzinc bromide $46,-78{ }^{\circ} \mathrm{C}, 56 \%$; b) DIBAI-H, THF, $-10{ }^{\circ} \mathrm{C}$, then $\mathrm{MeOH}$, then $\mathrm{NaBH}_{4}, \mathrm{MeOH} / \mathrm{THF}, \mathrm{RT}, 69 \%$; c) $\mathrm{BCl}_{3}, \mathrm{CH}_{2} \mathrm{Cl}_{2}, 0{ }^{\circ} \mathrm{C}$; d) bis(2-oxo-3-oxazolidinyl)phosphinic chloride (BOPCl), $\mathrm{CH}_{2} \mathrm{Cl}_{2}$, pyridine, then further BOPCl, RT; e) $\mathrm{Ph}_{3} \mathrm{PCl}_{2}, \mathrm{CH}_{3} \mathrm{CN}$, pyridine, RT, $61 \%$ (3 steps).
We found that exposure of the $\mathrm{Y}$-lactone to DIBAI-H led to rapid reduction ( $<20 \mathrm{~min}$ ) of the $y$-lactone to corresponding lactol (LRMS analysis), which on addition of methanol and excess sodium borohydride gave the triol $\mathbf{4 8}$. The PMB ester in $\mathbf{4 8}$ was readily removed by treatment with boron trichloride and the total synthesis was completed using the method of Corey, ${ }^{6 a}$ namely $\beta$ lactone formation using $\mathrm{BOPCl}$ and chlorination with triphenylphosphine dichloride to give salinosporamide $A(1)$. The analytical data for our synthetic salinosporamide $A$ were in excellent agreement for that of both the natural and previously synthesized material.

A summary of our synthesis is shown in Scheme 10. A number of points are worthy of comment. The synthesis allows the production of good quantities of key intermediates. We have prepared gram quantities of the carboxylic acid 39 which were transformed into gram quantities of the [3.3.0]-bicyclic $y$-lactone 43. From intermediate $\mathbf{4 3}$ we have prepared $645 \mathrm{mg}$ of the fully elaborated pyrrolidinone $\mathbf{4 7}$. We ultimately synthesized $30 \mathrm{mg}$ of the natural product although our route would undoubtedly allow us to prepare significantly more. The route proceeds in 16 steps ( $5 \%$ yield) from the commercially available sultam 30 (15 steps and $6 \%$ from commercially available sultam 31 ). For comparison, Corey's synthesis of 1 proceeds in 17 steps $(9.8 \%)$ from threonine, Fukuyama's synthesis of 1 proceeds in 14 steps (19\%) from 4pentenoic acid, and Romo's bioinspired synthesis of 1 in $90 \%$ ee, proceeds in 9 steps (3.6\%) from serine. The key features of the synthesis reported above include: the use of an oxidative radical 
cyclization for the synthesis of the key [3.3.0]-bicyclic $Y$-lactone $(+)$-36 with good diastereocontrol, a selenolactonization to set the required C-3 tertiary-alkoxy stereocenter giving $\mathbf{4 2}$, and the use of Corey's method for diastereoselective introduction of the cyclohexenyl side chain to give $\mathbf{4 7}$. Other notable aspects of our synthesis include the scalability of the route and the limited use of protecting groups as demonstrated by the unprotected amide/lactam $\mathrm{NH}$ being carried through the whole synthetic sequence.

\section{Conclusions}

In conclusion, we have developed a short enantioselective synthesis of the potent proteasome inhibitor salinosporamide A. Work is ongoing to synthesize more complex, biologically active, pyrrolidinone natural products using our oxidative radical cyclization methodology.

\section{Experimental Section}

Supporting Information. Experimental procedures; spectroscopic and analytical data for all new compounds including copies of NMR spectra.

\section{Acknowledgements}

We thank the EPSRC for funding this work. The John Fell Oxford University Press (OUP) Research Fund is gratefully acknowledged for an equipment grant. We thank the analytical sections of our Department for their excellent support. We are grateful to Prof. Danishefsky for providing spectroscopic data.

Keywords: Total synthesis $•$ Natural products $・$ Radical reactions

[1] R. H. Feling, G. O. Buchanan, T. J. Mincer, C. A. Kauffman, P. R. Jensen W. Fenical, Angew. Chem. Int. Ed. 2003, 42, 355-357; Angew. Chem. 2003, 115, 369-371.

[2] Throughout the manuscript solid and broken bold lines will be used for racemic compounds with two or more stereocenters and solid and broken wedges will be used for enantiopure compounds, see: H. Maehr, J. Chem Educ. 1985, 62, 114-120.

[3] M. Groll, R. Huber, B. C. M. Potts, J. Am. Chem. Soc. 2006, 128, 51365141.

[4] W. Fenical, P. R. Jensen, M. A. Palladino, K. S. Lam, G. K. Lloyd, B. C. Potts, Biorg. Med. Chem. 2009, 17, 2175-2180.

[5] T. A. M. Gulder, B. S. Moore, Angew. Chem. Int. Ed. 2010, 49, 93469367.

[6] a) L. R. Reddy, P. Saravanan, E. J. Corey, J. Am. Chem. Soc. 2004, 126, 6230-6231; b) L. R. Reddy, J. F. Fournier, B. V. S. Reddy, E. J. Corey, Org. Lett. 2005, 7, 2699-2701; c) A. Endo, S. J. Danishefsky, J. Am. Chem. Soc. 2005, 127, 8298-8299; d) T. T. Ling, V. R. Macherla, R. R. Manam, K. A. McArthur, B. C. M. Potts, Org. Lett. 2007, 9, 2289-2292; e) K. Takahashi, M. Midori, K. Kawano, J. Ishihara, S. Hatakeyama, Angew. Chem. Int. Ed. 2008, 47, 6244-6246; Angew. Chem. 2008, 120 , 6340-6342; f) T. Fukuda, K. Sugiyama, S. Arima, Y. Harigaya, T. Nagamitsu, S. Omura, Org. Lett. 2008, 10, 4239-4242; g) Y. Sato, H.
Fukuda, M. Tomizawa, T. Masaki, M. Shibuya, N. Kanoh, Y. Iwabuchi, Heterocycles 2010, 81, 2239-2246; h) H. Nguyen, G. Ma, D. Romo, Chem. Commun. 2010, 46, 4803-4805; i) N. Satoh, S. Yokoshima, T. Fukuyama, Org. Lett. 2011, 13, 3028-303; j) Y. Kaiya, J. Hasegawa, T. Momose, T. Sato, N. Chida, Chem. Asian. J. 2011, 6, 209-219; k) H. Nguyen, G. Ma, T. Gladysheva, T. Fremgen, D. Romo, J. Org. Chem. 2011, 76, 2-12.

[7] For total syntheses of 1 in racemic form see: a) N. P. Mulholland, G. Pattenden, I. A. S. Walters, Org. Biomol. Chem. 2006, 4, 2845-2846; b) G. Ma, H. Nguyen, D. Romo, Org. Lett. 2007, 9, 2143-2146; c) N. P. Mulholland, G. Pattenden, I. A. Walters, Org. Biomol. Chem. 2008, 6, 2782-2789.

[8] For formal syntheses of 1 see: a) V. Caubert, J. Massé, P. Retailleau, N. Langlois, Tetrahedron Lett. 2007, 48, 381-384; b) I. V. Margalef, L. Rupnicki, H. W. Lam, Tetrahedron 2008, 64, 7896-7901; c) T. Momose, Y. Kaiya, J. Hasegawa, T. Sato, N. Chida, Synthesis 2009, 2983-2991; d) R. A. Mosey, J. J. Tepe, Tetrahedron Lett. 2009, 50, 295-297; e) J. R. Struble, J. W. Bode, Tetrahedron 2009, 65, 4957-4967; f) T. T. Ling, B. C. Potts, V. R. Macherla, J. Org. Chem. 2010, 75, 3882-3885; g) A. W. J. Logan, S. J. Sprague, R. W. Foster, L. B. Marx, V. Garzya, M. S. Hallside, A. L. Thompson, J. W. Burton, Org. Lett. 2014, 16, 4078-4081.

[9] For recent reviews containing synthetic routes to salinosporamide A see: a) M. Shibasaki, M. Kanai, N. Fukuda, Chem. Asian. J. 2007, 2, 20-38; b) T. A. M. Gulder, B. S. Moore, Angew. Chem. Int. Ed. 2010, 49, 93469367; Angew. Chem. 2010, 122, 9734-9556; c) B. C. Potts, K. S. Lam, Marine Drugs 2010, 8, 835-880; d) A. Rentsch, D. Landsberg, T. Brodmann, L. Bulow, A. K. Girbig, M. Kalesse, Angew. Chem. Int. Ed. Engl. 2013, 52, 5450-5488; Angew. Chem. 2013, 125, 5560-5599.

[10] D. A. Evans, M. D. Ennis, D. J. Mathre, J. Am. Chem. Soc. 1982, 104, 1737-1739.

[11] W. Hess, J. W. Burton, Chem. Eur. J. 2010, 16, 12303-12306.

[12] B. Barlaam, T. G. Bird, C. Lambert-van der Brempt, D. Campbell, S. J. Foster, R. Maciewicz, J. Med. Chem. 1999, 42, 4890-4908.

[13] L. A. Carpino, D. Sadat-Aalaee, H. G. Chao, R. H. DeSelms, J. Am. Chem. Soc. 1990, 112, 9651-9652.

[14] A number of amide bond forming conditions were trialled including: TBTU, $i$ - $\mathrm{Pr}_{2} \mathrm{NEt}$; BOPCI, $i$ - $\mathrm{Pr}_{2} \mathrm{NEt}$; DCC, DIPEA; T3P, $\mathrm{Et}_{3} \mathrm{~N}$; HATU, $i$ - $\mathrm{Pr}_{2} \mathrm{NEt}$; DPPA, Et 3 N; $\mathrm{PivCl}, \mathrm{Et}_{3} \mathrm{~N}$.

[15] P. Kocienski, P. Raubo, J. K. Davis, F. T. Boyle, D. E. Davies, A. Richter, J. Chem. Soc., Perkin Trans. 1 1996, 1797-1808.

[16] For reviews of manganese(III) acetate in organic synthesis see: a) B. B. Snider, Chem. Rev. 1996, 96, 339-363; b) G. G. Melikyan, Org. React. 1997, 49, 427-675; c) A. S. Demir, M. Emrullahoglu, Curr. Org. Synth. 2007, 4, 321-351; d) J. W. Burton (2012) in Encyclopedia of Radicals in Chemistry, Biology and Materials, C. Chatgilialoglu and A. Studer (eds). John Wiley \& Sons Ltd, Chichester, UK, pp 901-942; e) M. Mondal, U. Bora, RSC Advances 2013, 3, 18716-18754.

[17] For a review of the mechanisms of manganese(III) acetate-mediated reactions see: B. B. Snider Tetrahedron, 2009, 65, 10738-10744.

[18] For some examples of the use of manganese(III) acetate in systems reacting with intermediate captodative radicals, see: (a) A. Citterio, A. Marion, A. Maronati, M. Nicolini, Tetrahedron Lett., 1993, 34, 7981-7984; (b) P. J. Crocker, U. Karlsson-Andreasson, B. T. Lotz, M. J. Miller, Heterocycles, 1995, 40, 691-716; (c) P. J. Crocker, M. J. Miller, J. Org. Chem., 1995, 60, 6176-6179.

[19] The pre-transition state assembly is a modified version of the BeckwithHouk model for the cyclization of 5-hexenyl radicals: a) A. L. J. Beckwith, C. H. Schiesser, Tetrahedron Lett. 1985, 26, 373-376; b) K. N. Houk, M. N. Paddonrow, D. C. Spellmeyer, N. G. Rondan, S. Nagase, J. Org. Chem. 1986, 51, 2874-2879.

[20] If the reaction is conducted at $40{ }^{\circ} \mathrm{C}$ the oxidized, uncyclized products predominate, in keeping with the $s$-cis radical 25 a being more stable than the $s$-trans radical $\mathbf{2 5 b}$.

[21] H. Asahara, K. Inoue, S. Tani, K. Umezu, N. Nishiwaki, Adv. Synth. Catal. 2016, 358, 2817-2828. 
[22] R. M. Scarborough, B. H. Toder, A. B. Smith, J. Am. Chem. Soc. 1980 102, 3904-3913.

[23] Attempted chemoselective lactone opening with phenylselanyl anion of the ethyl, i-propyl and benzyl esters corresponding to 23a was also unsuccessful.

[24] W. Oppolzer, R. Moretti, S. Thomi, Tetrahedron Lett. 1989, 30, 56035606.

[25] M. J. Batchelor, R. J. Gillespie, J. M. C. Golec, C. J. R. Hedgecock, S. D. Jones, R. Murdoch, Tetrahedron 1994, 50, 809-826.
[26] D. A. Evans, T. C. Britton, J. A. Ellman, Tetrahedron Lett. 1987, 28, 61416144.

[27] J. R. Dunetz, Y. Xiang, A. Baldwin, J. Ringling, Org. Lett. 2011, 13, 50485051.

[28] D. Liotta, U. Sunay, H. Santiesteban, W. Markiewicz, J. Org. Chem. 1981, 46, 2605-2610.

[29] V. Rodeschini, J.-G. Boiteau, P. Van de Weghe, C. Tarnus, J. Eustache, J. Org. Chem. 2004, 69, 357-373.

[30] H. C. Brown, R. F. McFarlin, J. Am. Chem. Soc. 1958, 80, 5372-5376. 
Entry for the Table of Contents (Please choose one layout)

Layout 1:

\section{FULL PAPER}

Text for Table of Contents

Layout 2:

\section{FULL PAPER}

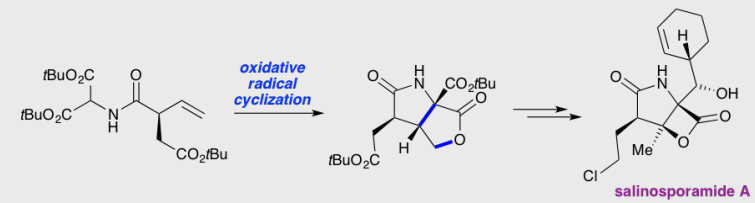

((Insert TOC Graphic here: max. width: $5.5 \mathrm{~cm}$; max. height: $5.0 \mathrm{~cm})$ )
Author(s), Corresponding Author(s)*

Page No. - Page No.

Title 